\title{
Energy flow of a 2018 FIA F1 racing car and proposed changes to the powertrain rules
}

https://doi.org/10.1515/nleng-2018-0171

Received November 12, 2018; revised December 3, 2018; accepted December 28, 2018.

Abstract: In the last few years, the different teams have dramatically improved the directly injected, electrically assisted turbocharged, internal combustion engine of FIA F1 hybrid electric cars. With limited fuel flow rate, but unlimited boost, the engine is now delivering peak power at fuel conversion efficiencies about $45 \%$ running lean stratified with the help of some sort of jet ignition. The paper analyses the energy flow of a FIA F1 hybrid electric car covering one lap of the Monte Carlo race track of length $3.370 \mathrm{~km}$. The amount of energy recovered is minimal, at the most 2 of the $9.77 \mathrm{MJ}$ of braking energy, or $20.6 \%$. The fuel consumption per lap, $1.16 \mathrm{~kg}$ of fuel, or $50.34 \mathrm{MJ}$ of fuel energy, needed to deliver the 16.28-18.28 MJ of propulsive energy, at an outstanding average efficiency of 32 to $36 \%$, may still be dramatically reduced. New rules are thus proposed to promote the development of technical features that could be beneficial to passenger car applications, from advanced turbo-compounding, to enhanced thermal and mechanical energy recovery, and better hybridization.

Keywords: internal combustion engines, turbocharging, electric hybrid vehicles, energy conversion, energy efficiency, racing cars, FIA F1, Monte Carlo

\section{Introduction}

FIA F1 racing is characterized by restrictive rules, with limited freedom to develop the different components of the power unit. The internal combustion engine today represents only one element of a sophisticated, complex, power unit [1]. The FIA F1 power unit comprises an internal

\footnotetext{
*Corresponding Author: Albert Boretti, Department for Management of Science and Technology Development, Ton Duc Thang University, Ho Chi Minh City, Vietnam and Faculty of Applied Sciences, Ton Duc Thang University, Ho Chi Minh City, Vietnam, E-mail: albertoboretti@tdtu.edu.vn
}

combustion engine (ICE), a motor generator unit-kinetic (MGU-K), a motor generator unit-heat (MGU-H), an energy store (ES), a turbocharger (TC) and the control electronics (CE) [1].

In the last few years, the different teams have dramatically improved the directly injected, electrically assisted turbocharged, ICE, of limited fuel flow rate but unlimited boost, now delivering peak power at fuel conversion efficiencies about $45 \%$ running lean stratified with the help of some sort of jet ignition. The different teams have, however, also developed illegal systems to improve performances, from fuel flow meters out of calibration, to combustion of lubricating oil, to the use of special fuels, and strictly speaking, also the use of jet ignition, [2, 3].

The energy flow of a F1 car covering a lap of Monte Carlo is analyzed in detail. It is shown as the amount of energy recovery is minimal, and dramatic improvements are still possible to reduce the fuel consumption per lap. There is a clear need to develop new rules to promote the development of technical features that could be beneficial to passenger car applications, from advanced turbocompounding, to enhanced energy recovery. It is suggested to leave complete freedom to develop the ICE, as well as the energy recovery system, without any limitation of recoverable energy or flow rate, but drastically reducing the amount of pump fuel permitted per race.

The aim of the present work is to present, with the support of measurements and computations, the state-of-theart of energy efficiency in FIA F1 racing, and to discuss the further evolution of the rules to make F1 more technically challenging for the benefit of production cars. The paper will give first an historical perspective of FIA F1 racing from the start of the competition in 1950 to the present times. Then, results of experiments and simulations will be shown for a F1 car covering one lap of Monte Carlo, deriving energy flows and energy efficiency. Then, the new rules, to be introduced in 2021, will be discussed, as they are likely to be, and as they should be changed, to make F1 more technically challenging and beneficial to production cars. 


\section{Past of FIA F1}

The history of turbocharged racing engines, with emphasis on FIA F1, FIA WEC and FIA WRC, is covered in [4]. The interested reader is thus referred to this book for further reading. The rules of the Fédération Internationale de l'Automobile (FIA) F1 power units, now including the internal combustion engine (ICE) and the Energy Recovery Systems (ERS), have never been so restrictive, since the start of these competitions. This introductory part is needed to forecast the future developments, as any change should be considered in the context of the legacy to the world most successful motorsport event.

The FIA F1 Power Units 1950 to present have been changed significantly over the years, promoting first supercharged engines, then naturally aspirated engines, then turbocharged engines, again naturally aspirated engines, and finally again turbocharged engines.

In the beginning, pre-World War II (WWII) regulations defined by engine capacity for supercharged and naturally aspirated engines were adopted. The first ever FIA F1 World Championship was organized in 1950, in response to the FIM Motorcycle World Championships introduced in 1949. During the years 1950-1953, engines were 4.4-liter naturally aspirated or 1.5-liter forced induction (supercharged). Engine speed and number and configurations of engine cylinders were unrestricted. Pre-WWII Alfa Romeo Alfettas 158s, powered by a $425 \mathrm{HP}, 1.5$-litre, supercharged gasoline engine, dominated the first two seasons despite the tiny budget, using mostly pre-WWII technology as well as parts.

The first strictly FIA F1 regulations were introduced in the 1954 season and continued until 1960. Engines were either 2.5-litre naturally aspirated, or 0.75 -litre forced induction. Engine speed and number and configurations of engine cylinders were unrestricted. The 2.5-litre naturally aspirated engine was the prevailing technical solution.

1961 to 1965 , only 1.5-litre naturally aspirated engines were permitted, forced induction being prohibited. Engine speed and number and configurations of engine cylinders were unrestricted.

From 1966, due to the competition of the much better performance sport cars featuring larger engines, the FIA introduced much larger displacements in naturally aspirated engines, 3-litre, while also permitting 1.5-litre forced induction engines. Engine speed and number and configurations of engine cylinders were unrestricted. Despite permitted, no manufacturer had in the beginning the resources needed to develop a turbocharged engine.
It was in the late 1970s that F1 became a business, with significant expenditure also brought by the turbos and other technologies. It was only in 1977 that Renault introduced their V6 1.5-litre turbocharged engine that quickly proved to be the winning solution. Different turbocharged engines configurations were considered. By 1985, all the manufacturers adopted 1.5-litre turbocharged engines. In 1986, only engines 1.5-litre forced induction (turbocharged) were permitted. In 1987, 3.5-litre naturally aspirated engines were permitted together with 1.5-litre forced induction (turbocharged) engines of 3.5 bar boost limit. In 1988, the boost of 1.5-litre turbocharged engines was reduced to $2.5 \mathrm{bar}$, and the year after the forced induction engines were banned. In 1986, the turbocharged engines were delivering $900 \mathrm{HP}$ during races, and 1,400 HP during qualifying. The turbo domination lasted two more years, in 1987 and 1988, despite much larger 3.5-litre naturally aspirated engines were permitted.

The years 1989 to 1994 were characterized by using 3.5litre naturally aspirated engines, with banned forced induction. The revolution limit was unrestricted, while the number of cylinders was limited to V12. Reduction of displacement and number of cylinders drove the change in the engine rules adopted during the decade 1995 to 2005. Only 3.0-litre naturally aspirated engines were permitted, while forced induction was banned. The revolution limit was unrestricted, while the number of cylinders was limited to V12 until 1999, then V10 maximum. In 2005, the FIA introduced new ancillary regulations limiting to one engine per two Grand Prix weekends, to increase reliability and reduced power.

A further reduction of displacement and number of cylinders to limit performances, determined the rules 2006 to 2013. The engines were 2.4-litre naturally aspirated. Forced induction (turbocharged) engines were banned. The revolution limit was unrestricted until 2006, then 19,000 rpm in 2007 and 2008, then 18,000 rpm since 2009. The engine configuration was compulsory $90^{\circ}$ V8. Bore was restricted to a maximum of $98 \mathrm{~mm}$. Number of valves per cylinder was not more than two intake and two exhaust valves. Only one fuel injector was permitted per cylinder, and not more than one spark plug. More severe restrictions were also placed on the materials. The engine specifications were then basically frozen since 2007 , thus producing very similar products across different manufacturers, mostly using same suppliers.

The global financial crisis of 2008 brings the emphasis on sustainability, with the most part of the manufacturers unable to afford the high costs of F1. Cost cutting, and departure of factory teams characterized the period 2009 to 2013. The novelty was hybridization. In 2009, kinetic 
energy recovery systems (KERS), were permitted, with a maximum power of $60 \mathrm{~kW}$ and energy capacity of $400 \mathrm{~kJ}$. Electro-mechanical, mechanical and electric KERS were proposed. Initially, KERS did not translate in any performance improvement, and, nobody used in 2010. KERS returned in 2011, and took over in 2013, also in view of the new 2014 rules.

\section{Present of FIA F1}

The new turbo era started in 2014. This time naturally aspirated engines were banned. The turbocharged engines were 1.6-litre, with engine speed limited to $15,000 \mathrm{rpm}$ and cylinders' configuration strictly $90^{\circ} \mathrm{V} 6$. The engine must have two intake and two exhaust valves per cylinder and a single turbocharger. The new regulations included multiple energy recovery systems, a KERS of increased power and energy, renamed Motor Generator Unit-Kinetic (MGU$\mathrm{K}$ ), and a Motor Generator Unit-Heat (MGU-H) connected to the turbocharger shaft. The MGU-H was introduced with the purpose to improve low speed boost and remove turbolag more than recover the waste energy, Boretti [? ] to [7]. The Energy recovery systems (ERS) had maximum power of $120 \mathrm{~kW}$ and $2 \mathrm{MJ}$ per lap. Fuel flow restrictions were also introduced. The fuel flow to the engine was limited to $100 \mathrm{~kg} / \mathrm{h}$. The number of engines per season was drastically limited, and engine development was also diminished. The move to attract more commercial partners was made at the expense of further standardization and further reduced freedom to technically develop competitive power train solutions.

The new power unit consists of six separate elements, Fig. 1 (image reproduced modified after [8]), the internal combustion engine (ICE), the motor generator unit-kinetic (MGU-K), the motor generator unit-heat (MGU-H), the energy store (ES), the turbocharger (TC) and the control electronics (CE). Each driver is permitted to use only three ICE, MGU-H and TC, and only two ES, CE and MGU-K during one season. A maximum of $4 \mathrm{MJ}$ per lap can be transferred from the ES to the MGU-K. A maximum of 2 MJ per lap can be transferred from the MGU-K to the ES. An unlimited amount of energy can be transferred between the MGU-H and the ES and/or MGU-K. The MGU-K may only be used during a race start once the car has reached $100 \mathrm{kph}$.

The KERS is by rules an electric motor generator connected to a battery, not because this technology is superior to any other technology, but simply by decision of the FIA to focus on a specific product. This choice is dictated by political deliberations. Differences between products of different manufacturers are small. As the costs for a season are lately increasing, not reducing, it does not make any sense to limit with resources restriction, strict rules, and off-the-shelf components the freedom to achieve better performances by genuine technical development.

One healthy technical development carried out by the manufacturers has been the introduction of jet ignition, that albeit strictly speaking illegal - only one direct injector is allowed per cylinder - has permitted stable operation lean burn stratified. Also, interesting has been the turbocompounding. The MGU-H is used to cancel the turbo-lag during accelerations and reshape the steady low speed torque curve. The MGU-H is not yet used to improve the fuel conversion efficiency, drastically reducing the waste heat in the exhaust, simply because it is not required to do so. The ES plus the MGU-H could have been used not only as E-BOOST, but also as a waste heat recovery system (WHRS).

With $105 \mathrm{~kg}$ of theoretically pump fuel permitted per race, and the maximum flow rate limited to $100 \mathrm{~kg} / \mathrm{h}$, some manufacturers have indeed adopted burning of oil mixed to specifically developed additives to increase performances. After months of use, "suspicions" these practices were exploited prompted the FIA, to limit oil consumption to 1.2 liters per $100 \mathrm{~km}$ [2], [3].

Thanks to direct injection and jet ignition, the best F1 engines of the 2018 season are delivering peak power at fuel conversion efficiencies well above the $40 \%$ previously considered as a target [10], approaching the $45 \%$ mark, [9]. The total power of the ICE plus the MGU-K is optimistically claimed to approach 1,000 HP ( $745 \mathrm{~kW})$. A maximum MGUK power of $120 \mathrm{~kW}$ requires an ICE power output of $625 \mathrm{~kW}$. With a pump gasoline fuel of LHV $43.4 \mathrm{MJ} / \mathrm{kg}$, a fuel flow rate limited to $100 \mathrm{~kg} / \mathrm{h}$ translates in $1,206 \mathrm{~kW}(1,617 \mathrm{HP})$ of fuel flow power. While a fuel conversion efficiency of 50\% that may deliver $603 \mathrm{~kW}$ (808 HP) is possibly still far from being achieved, the $482 \mathrm{~kW}$ (or $647 \mathrm{HP}$ ) that still require a $40 \%$ fuel conversion efficiency have been surpassed. Very likely, the best engines can run at about $45 \%$ fuel conversion efficiency delivering $543 \mathrm{~kW}$ (728 HP) of peak power working lean stratified. No production turbocharged gasoline engine has delivered so far similar efficiencies. This is a huge improvement towards the turbocharged engines of the past, that running slightly fuel rich for peak power, were delivering much less in terms of fuel conversion efficiency. 


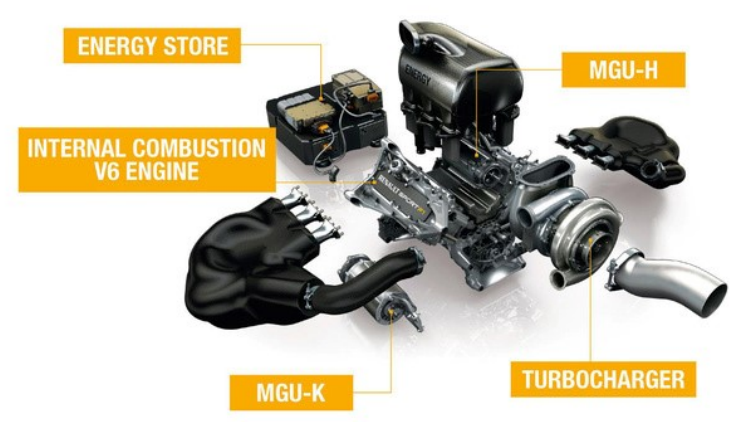

Fig. 1: F1 KERS (ES+MGU-K) and E-BOOST/WHR (ES+MGU-H) from [8]

\section{Energy flow during one lap in Monte Carlo}

Fig. 2 presents the velocity of a F1 car covering a 1.15.100 lap in Monte Carlo. This circuit has a length of $3.34 \mathrm{~km}$. The race distance is 78 laps or $260.52 \mathrm{~km}$. With reference to the configuration adopted since 2003, the "Tabac" corner has been slightly moved in 2015 ("Tabac" is a constricted fourth gear corner so called because a tobacconist shop was located on the outside of the corner). Maximum speed is about $293 \mathrm{kph}$ and minimum speed is $47 \mathrm{kph}$. Average corner speed is $102 \mathrm{kph}$. Downforce level of car aerodynamic is high, while aerodynamic efficiency ratio is very low. The engine is full throttle $43 \%$ of the time. There are 12 braking events and 35 gear changes per lap. In 2018, fastest lap in race was 1:14.260. In qualifying, best lap was 1:10.810. The cars must weigh at least $733 \mathrm{~kg}$, including the driver and all his safety equipment but not the fuel, always during an event. The telemetry data are confirmed by a lap time simulation by using the Optimum G software [11].

Fig. 3 presents the longitudinal acceleration of the car. To be noted, the maximum acceleration is $18.01 \mathrm{~m} / \mathrm{s}^{2}$, but the minimum acceleration is $-64.11 \mathrm{~m} / \mathrm{s}^{2}$. Hence, while positive accelerations are at the most $1.84 \mathrm{~g}$, decelerations (braking) are $-6.54 \mathrm{~g}$.

To analyze the energy flow, propulsive and braking energies must be computed from the velocity schedule. This is done by using a simplified car equation only accounting for the mass of the car and the aerodynamic and rolling resistances.

If $\mathrm{F}_{P / B}$ is the propulsion or the braking force and $\mathrm{F}_{R}$ is the retarding force due to the aerodynamic drag and the rolling resistance in $\mathrm{N}$, then

$$
\left(F_{P / B}-F_{R}\right)=m \cdot a
$$

where $\mathrm{m}$ is the mass of the car in $\mathrm{kg}$ and $\mathrm{a}$ is the acceleration in $\mathrm{m} / \mathrm{s}^{2}$. The mass of the car is taken as $760 \mathrm{~kg}$.

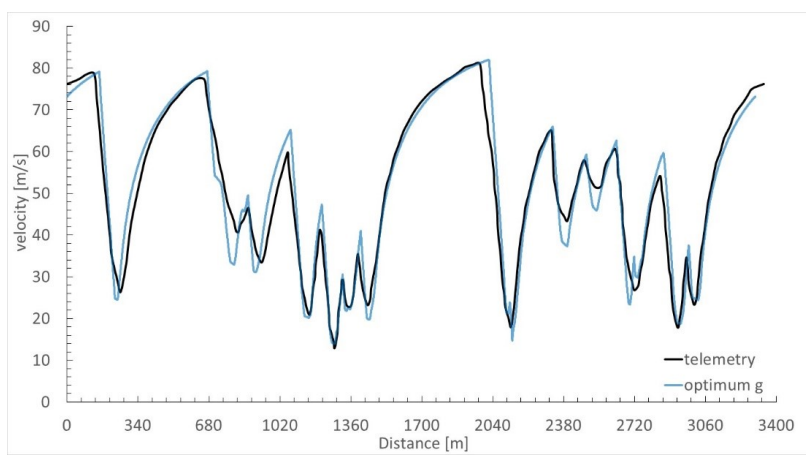

Fig. 2: Velocity of a F1 car covering a 1.15.100 lap in Monte Carlo

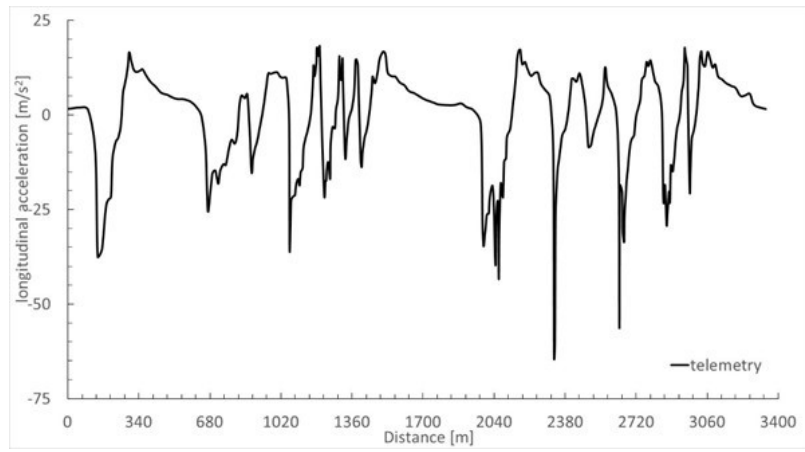

Fig. 3: Acceleration of a F1 car covering a 1.15.100 lap in Monte Carlo

For what concerns the aerodynamic drag, the aerodynamic drag force is

$$
F_{R, A}=1 / 2 \cdot \rho \cdot v^{2} \cdot C_{D} \cdot A
$$

where $\rho$ is the air density, $C_{D}$ is the drag coefficient and $\mathrm{A}$ is the frontal car area. $\mathrm{V}$ is the velocity in $\mathrm{m} / \mathrm{s}$. We take $\rho=1.205 \mathrm{~kg} / \mathrm{m}^{3}, \mathrm{C}_{D}=0.85$ for a reference area $\mathrm{A}=1.5 \mathrm{~m}^{2}$.

For what concern the rolling resistance, we take the rolling force as

$$
F_{R}=c \cdot m \cdot g
$$

where $\mathrm{c}$ is the rolling resistance coefficient - dimensionless and $\mathrm{g}$ is the acceleration of gravity, $9.81 \mathrm{~m} / \mathrm{s}^{2}$. The rolling coefficients for air filled tires of normal passenger cars on dry roads is [12]

$$
c=0.005+(1 / p) \cdot\left[0.01+0.0095(v / 3.6 / 100)^{2}\right]
$$

where $\mathrm{p}$ is the tire pressure (bar) and $\mathrm{v}$ is the velocity (m/s). We may use this formula with $\mathrm{p}=2.5$ bar for an optimistic estimation of the rolling friction losses of a F1 car. We get $\mathrm{c}=\mathrm{a}+\mathrm{b} \cdot \mathrm{v}^{2}$ where $\mathrm{a}=9.00 \cdot 10^{-3}$ and $\mathrm{b}=4.92 \cdot 10^{-6} \mathrm{~s}^{2} / \mathrm{m}^{2}$.

Fig. 4 presents the longitudinal forces acting on the car, aerodynamic, rolling friction and inertia forces.

These forces are balanced at any time by the propulsive force delivered by the ICE and the MGU-K working 

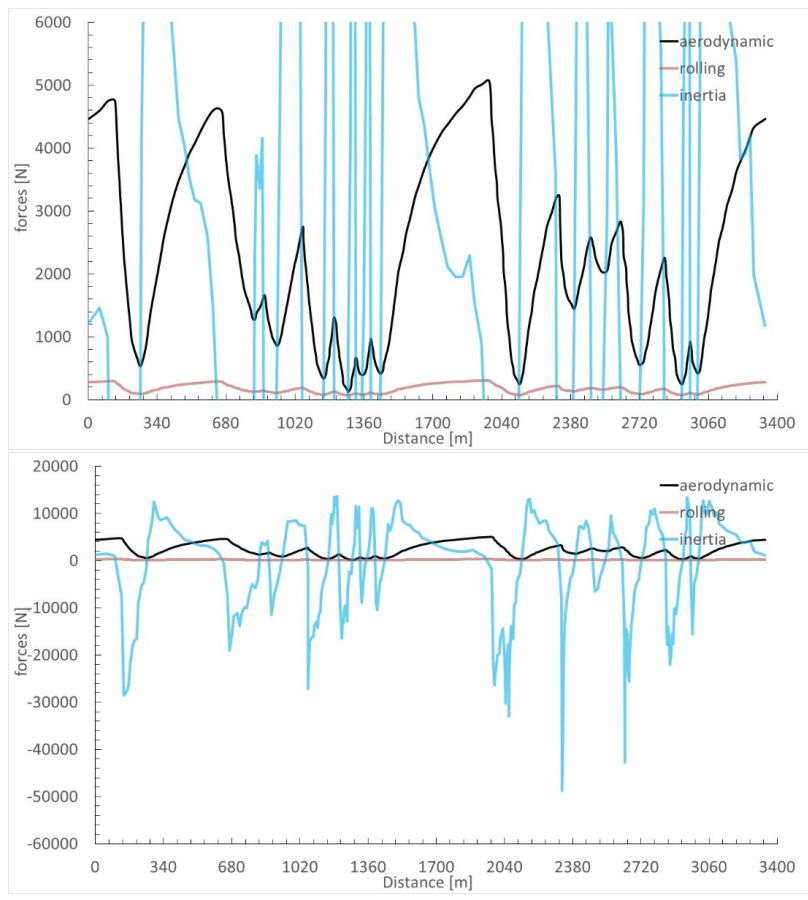

Fig. 4: longitudinal forces acting on the car, aerodynamic, rolling friction and inertia forces

as motor and the braking force produced by the friction brakes and the MGU-K working as generator. The inertia forces are much larger than the aerodynamic forces, that are much larger than the rolling friction forces. The positive force is much smaller than the negative force.

The propulsive and braking powers are the product of propulsive and braking forces by velocity

$$
P_{P / B}=F_{P / B} \cdot v
$$

with $\mathrm{P}$ in $\mathrm{W}$. This analysis returns the "reference" propulsion and braking forces and powers from the velocity schedule and the above environmental variables. From the propulsion and braking powers, then the propulsive and braking energies are computed by time integration with values in $\mathrm{J}$.

Fig. 5 presents the propulsive and braking powers. While the maximum propulsive power is $683.16 \mathrm{~kW}$, the minimum power, i.e. the braking power, is $-2790.07 \mathrm{~kW}$. A MGU-K of power $120 \mathrm{~kW}$ helps very little to recover the braking energy while permitting same of friction brakes braking performances. While braking is obtained by combining both friction and MGU-K generator braking forces, regenerative braking may only be conducted strategically when there is no need to defend or to gain a position or make a good lap time.

Despite integration of friction and regenerative braking has been improved dramatically since the introduction of the first kinetic energy recovery systems in F1 in 2009, the maximum braking power of friction brakes is much larger than the regenerative braking power, limited to only $120 \mathrm{~kW}$ (in Fig. 5, the friction braking power exceeds 2000 $\mathrm{kW})$. Thus, when very sharp braking events are needed, there is very little space for regenerative braking [13], and drivers do not use when challenging or defending positions or trying their best lap.

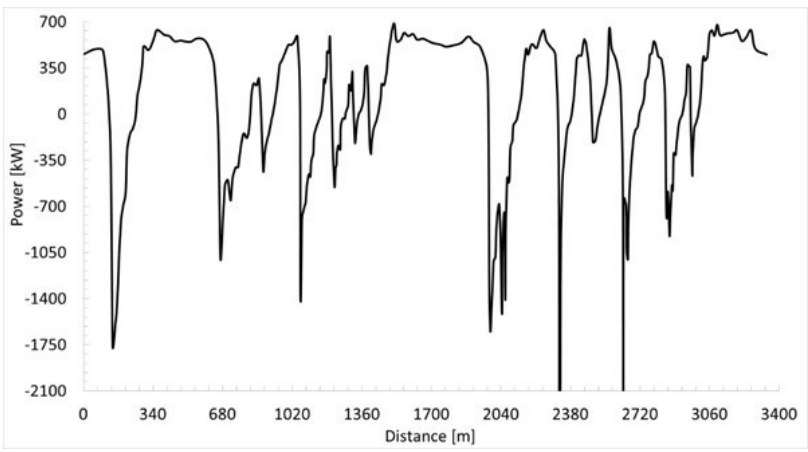

Fig. 5: Propulsive and braking power

Fig. 6 finally presents the propulsive and braking energies, and the braking energy that optimistically could be recovered by a perfect integration of friction and MGU-K generator forces. The total propulsive energy is $18.28 \mathrm{MJ}$. The total braking energy is more than one half, $-9.77 \mathrm{MJ}$. With a perfect integration of friction and regenerative brakes, the recoverable energy ( $72 \%$ round trip) could be $-2.02 \mathrm{MJ}$, i.e. the total propulsive energy requested to the internal combustion engine could be reduced to $16.26 \mathrm{MJ}$. By rules, the recoverable energy is limited to $2.00 \mathrm{MJ}$.

In the specific lap, as regenerative braking unfortunately translates in an increased lap time, the recovered energy is very likely zero, while some of the recovered energy of previous lap is used to produce the extra torque vs. the internal combustion engine only used during the lap.

The $120 \mathrm{~kW} 2 \mathrm{MJ}$ per lap formula permits to recover only a minimal amount of the braking energy. If energy efficiency could be the driving force behind powertrain developments, there is no reason why we should not target a much larger portion of the $9.77 \mathrm{MJ}$ of braking energy, about $50 \%$ of the $18.28 \mathrm{MJ}$ of propulsive energy. While presently the ICE must supply almost the totality of the $18.28 \mathrm{MJ}$ of propulsive energy per lap, with a perfect kinetic energy recovery system there is still the opportunity to cut $50 \%$ the fuel energy requirement. $2 \mathrm{MJ}$ over $9.77 \mathrm{MJ}$ of potentially recoverable energy is only $20 \%$. Additionally, with larger powers of the MGU-K it would be possible to recover more at the expenses of a reduced regenerative braking in- 
efficiency. But braking never occurs with so low power as $120 \mathrm{~kW}$ during good laps. Besides, when needed to accelerate the car, the extra power of the MGU-K could further improve the acceleration and top speed performance.

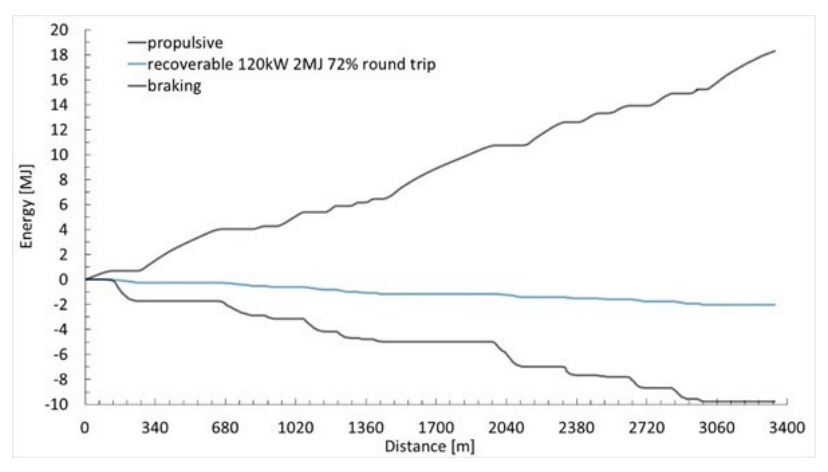

Fig. 6: Propulsive and braking energy

Regarding the $18.28 \mathrm{MJ}$ of propulsive energy, the chemical energy needed in the engine has certainly been drastically reduced by using lean stratified combustion, but it is still more than three times the mechanical propulsive energy. Recovery of waste energy, both exhaust and coolant, is again potentially rewarding, as about $2 / 3$ of the chemical energy is lost in the exhaust and coolant. Hence, a larger expenditure for healthy technical development is more than welcomed, possibly coming from cuts in the other expenditures characterizing F1 teams.

While it is mentioned that the fuel consumptionper lap in Monte Carlo is $1.5 \mathrm{~kg}$, which is low, as this racetrack has the lowest fuel effect of the year [14], the correct units are likely liters, rather than $\mathrm{kg}$, as the number of laps is 78 and the F1 cars may use no more than $105 \mathrm{~kg}$ of fuel in each race [15]. Hence, the fuel consumption is more likely 1.5 liter per lap, or $1.16 \mathrm{~kg}$ per lap, by taken the density of gasoline $0.77 \mathrm{~kg} /$ liter. A fuel consumption of $90.09 \mathrm{~kg}$ over the race is certainly much more realistic. With a fuel consumption estimated at $1.16 \mathrm{~kg}$ per reference lap, that on average is much slower than the 1.15 .100 time of the lap in Fig 2, a LHV of $43.4 \mathrm{MJ} / \mathrm{kg}$ translates in $50.34 \mathrm{MJ}$ of fuel energy per lap. This translates in a fuel conversion efficiency of $32 \%$ if we consider the propulsive power of $18.28 \mathrm{MJ}$ reduced of the $2 \mathrm{MJ}$ of recoverable energy, and $36 \%$ if we do not consider the energy recovered. Great things have thus been done for both peak power efficiency, and average efficiency over a lap, and more can still be done. The fuel conversion efficiency of the internal combustion engine may be further improved, as with 32 to $36 \%$ fuel energy conversion efficiencies, the most part of the fuel energy used in a cycle is still lost in coolant and exhaust waste heats. How- ever, the amount of braking energy recovered must also improve, as the recoverable $2 \mathrm{MJ}$ are only $20 \%$ of the total braking energy in the example considered. More use of the MGU-H, and adoption of larger and more efficient MGU-K and ES, are the first changes needed.

\section{The Future of FIA F1}

F1 should permit much more freedom in the definition of the ICE and the energy recovery. As the goal of the rules should be the lowering of the fuel consumption while keeping high the technical and sporting interest, the best solution is more freedom to achieve the fastest car within more stringent limits of fuel economy. This would benefit the racing and the everyday car.

A real limit should be set to the maximum amount of fuel to be used for a fixed distance race, and the engineers should be, then, left free to develop the hybrid power unit with, at the most, a prescribed displacement of the engine. The present limit of $105 \mathrm{~kg}$ of fuel per race is not restrictive enough, and the teams are not forced to recover even the $2 \mathrm{MJ}$ of energy permitted for every lap. Certainly, they have no interest to recover even the $2 \mathrm{MJ}$ if this must be done with only $120 \mathrm{~kW}$ of power. Finally, a specific battery and motor hybridization is too limiting. With so many energy conversion, chemical to electric to mechanical and viceversa, there may be alternative option, for example a fully mechanical system, of better round-trip efficiencies.

This is, however, not the direction in which the FIA is moving. The proposal is opposite, designed to simplify engine designs and cut costs of technical developments. The 1.6-liter V6 configuration will be very likely retained in the future, but the Motor Generator Unit-Heat (MGU-H) system, the only present component free to be further studied and developed, and potentially contributing to the valuable outcome of better waste heat recovery, will be very likely removed (discussions are still ongoing). The Motor Generator Unit-Kinetic (MGU-K) will be more powerful, with a more flexible use. The proposal calls for the introduction of "standardized components" and design parameters to make components produced by all manufacturers compatible with one another. Obviously, the hybridization system will be the same battery based electric. The discussions over the $2021 \mathrm{~F} 1$ powertrain regulations are ongoing. 


\section{Conclusion}

In the history of $\mathrm{F} 1$, technical rules have never been so restrictive in preventing healthy research and development of power trains that may bring benefits to road transport as those supposed to be adopted shortly. Healthy technical improvements may only follow the freedom to push technical boundaries.

There is a clear need to develop new rules to promote the development of technical features that could be beneficial to passenger car applications, from advanced turbocompounding, not limited to specific battery based electric, but of any type, including mechanic, to enhanced energy recovery, here again, not limited to specific battery based electric, but of any type, including mechanic.

Based on the energy analysis provided of a lap in Monte Carlo it is suggested to leave complete freedom to develop the internal combustion engine, as well as the kinetic energy recovery system, without any limitation of recoverable energy or flow rate, only drastically reducing the amount of pump fuel permitted per race.

Acknowledgement: The author received no funding and has no conflicts of interest to declare.

\section{References}

[1] formula1.com, 2018, "Power unit and ERS," www.formula1.com/en/championship/insidef1/understanding-f1-racing/Energy_Recovery_Systems.html

[2] roadandtrack.com, 2017, "How Today's F1 Engines Can Burn Oil to Make More Power," www.roadandtrack.com/motorsports/a13132940/how-todaysf1-engines-can-burn-oil-to-make-more-power/
[3] autosport.com, 2018, "How Formula 1 engine rules are tightening for the 2018 season," www.autosport.com/f1/news/134255/fresh-clampdown-onf1-engine-tricks-for-2018

[4] A. Boretti, 2019, "Advances in Turbocharged Racing Engines," To be Published By: SAE International. PT-199. [5]A. Boretti, 2012, “KERS Braking for 2014 F1 Cars," SAE P. 2012-01-1802, 2012.

[5] A. Boretti, 2013, "F1 2014: TURBOCHARGED AND DOWNSIZED ICE AND KERS BOOST," World Journal of Modelling and Simulation, Vol. 9, No. 2, pp. 150-160.

[6] A. Boretti, 2017, "F1 style MGU-H applied to the turbocharger of a gasoline hybrid electric passenger car," Nonlinear Engineering, doi.org/10.1515/nleng-2016-0069.

[7] A. Boretti, 2018, "Changes of E-KERS rules to make F1 more relevant to road cars," Advances in Technology Innovation, vol. 3, no. 1, pp. 26-35.

[8] D. Carney, 2014, "New rules shuffle the F1 deck," SAE International Magazine Feature Article14MEIP06_03. saemobilus.sae.org/content/14MEIP06_03.

[9] A. Boretti, 2019, "Progress of direct injection and jet ignition in throttle controlled engines," SAE P. 2019-26-0045.

[10] A. Boretti, 2012. Towards 40\% efficiency with BMEP exceeding 30 bar in directly injected, turbocharged, spark ignition ethanol engines. Energy conversion and management, vol. 57, pp.154-166.

[11] OptimumG, 2018, "OptimumLap," www.optimumg.com/software/optimumlap/ www.formula1.com/en/championship/inside-f1/rulesregs/Fuel_Fuel_system_fuel_usage_and_refuelling.html

[12] engineeringtoolbox.com, 2008, "Rolling Resistance," www.engineeringtoolbox.com/rolling-friction-resistanced_1303.html

[13] A. Boretti, 2013, "Kinetic Energy Recovery Systems for Racing Cars," Published By: SAE International, Product Code: PT-159. books.sae.org/book-pt-159/

[14] mclaren.com, 2017, "MONACO TRACK TIPS AND CIRCUIT STATS," www.mclaren.com/formula1/2017/monaco-grandprix/track-tips-and-circuit-stats/

[15] formula1.com, 2018, "Fuel, fuel usage and refueling," www.formula1.com/en/championship/inside-f1/rulesregs/Fuel_Fuel_system_fuel_usage_and_refuelling.html 